\title{
Metotrexato en condromatosis sinovial: una serendipia
}

\author{
C. Ascimani Peña, E. Saturansky \\ Servicio de Reumatología. Sanatorio “Julio Méndez”- ObSBA.
}

\section{Resumen}

La condromatosis sinovial es una metaplasia idiopática benigna de la membrana sinovial que afecta a $1 / 100.000$ habitantes, en una relación hombre/mujer de 3 a 1 entre los 30 y 50 años. Predomina en grandes articulaciones como rodilla $(70 \%)$, cadera $(20 \%)$ y hombro (19\%), y en menor proporción en codo y tobillo. Puede ser primaria 0 secundaria.

La etiología es desconocida. La resolución es quirúrgica ya sea por artroscopia o por cirugía a cielo abierto, no existiendo otra alternativa terapéutica.

Se presenta el caso clínico de un paciente con condromatosis sinovial en hombro derecho, que se comporta como una artropatía erosiva, indicándose metotrexato y resolviendo casi totalmente los nódulos condromatosos.

Palabras clave: condromatosis sinovial, tratamiento no quirúrgico, efecto antiproliferativo del metotrexato.

\section{Abstract}

The synovial chondromatosis is a benign idiopathic metaplasia of the synovial membrane which affects one in 100,000 inhabitants. It is 3 times more common in males, aged between 30 and 50 years old. It is commonly found in large joints such as knee (70\%), hip (20\%) and shoulder (19\%) and less frequently in elbow and heel. It can be primary or secondary. The etiology is still unknown.

The resolution is surgical by means of arthroscopy or open surgery, existing no other therapeutic alternatives.

We present a male patient with primary synovial chondromatosis in the right shoulder, leading to an erosive arthropathy. Treatment with methotrexate resolved almost entirely the cartilaginous nodules.

Key words: chondromatosis synovial, nonsurgical treatment, antiproliferative effect of methotrexate

\section{Introducción}

La condromatosis sinovial es una metaplasia idiopática benigna de la membrana sinovial que afecta a 1/100.000 habitantes, en una relación hombre/mujer de 3 a 1 entre los 30 y 50 años. Predomina en grandes articulaciones como rodilla $(70 \%)$, cadera $(20 \%)$ y hombro $(19 \%)$, y en menor proporción en codo y tobillo. Raramente se presenta en pequeñas articulaciones de manos, pies y temporomaxilar, $\mathrm{y}$ pocas veces en localizaciones extraarticulares como ligamentos, vainas tendinosas y bursas. Puede ser primaria o secundaria. La etiología es desconocida aunque se ha asociado a alteraciones cromosómicas ${ }^{1}$. Milgram describió tres estadios: 1) enfermedad intraarticular activa sin cuerpos libres, 2) lesiones transicionales con proliferación sinovial y cuerpos libres y 3 ) cuerpos libres sin enfermedad sinovial $^{2}$. Se presenta malignización del $1-5 \%$ de los casos. La resolución es quirúrgica ya sea por artroscopia o por cirugía a cielo abierto, no existiendo otra alternativa terapéutica.

\section{Caso clínico}

Paciente de 74 años, de sexo masculino, conductor de taxi, tabaquista, que comienza en febrero de 2009 con dolor, inflamación e impotencia funcional en hombro derecho. Es referido al Servicio de Reumatología en el año 2011 por aumento de la intensidad del dolor que no mejora con AINES, luego de artroscopia.

$\mathrm{Al}$ examen físico presenta aumento de la temperatura local, tumefacción y marcado dolor a la movilización activa y pasiva.

Se descartan causas de condromatosis sinovial secundaria (traumáticas y/o inflamatorias).

Se deriva al Servicio de Traumatología para tratamiento quirúrgico donde se realiza extirpación completa con estudio histopatológico compatible con condromatosis sinovial.

A los pocos meses, consulta nuevamente por dolor intenso sin mejoría luego de la cirugía. Se realiza $\mathrm{Rx}$ simple que muestra recidiva de las imágenes y se indica tratamiento con indometacina $75 \mathrm{mg}$ cada $12 \mathrm{hs}$, colchicina $1 \mathrm{mg}$ diario e infiltración con esteroide. A las dos semanas continúa con dolor intenso e impotencia funcional, por lo que se indica meprednisona $8 \mathrm{mg}$ diarios. Por presentar una mejoría muy leve, se decide agregar metotrexato 10 mg semanales, respondiendo con disminución paulatina del dolor. A los dos meses se presenta asintomático, con notable mejoría de la movilidad articular, por lo que se disminuye paulatinamente la corticoterapia.

$\mathrm{Al}$ año se realizan $\mathrm{Rx}$ y RMN de hombro que evidencian importante disminución de las imágenes. 


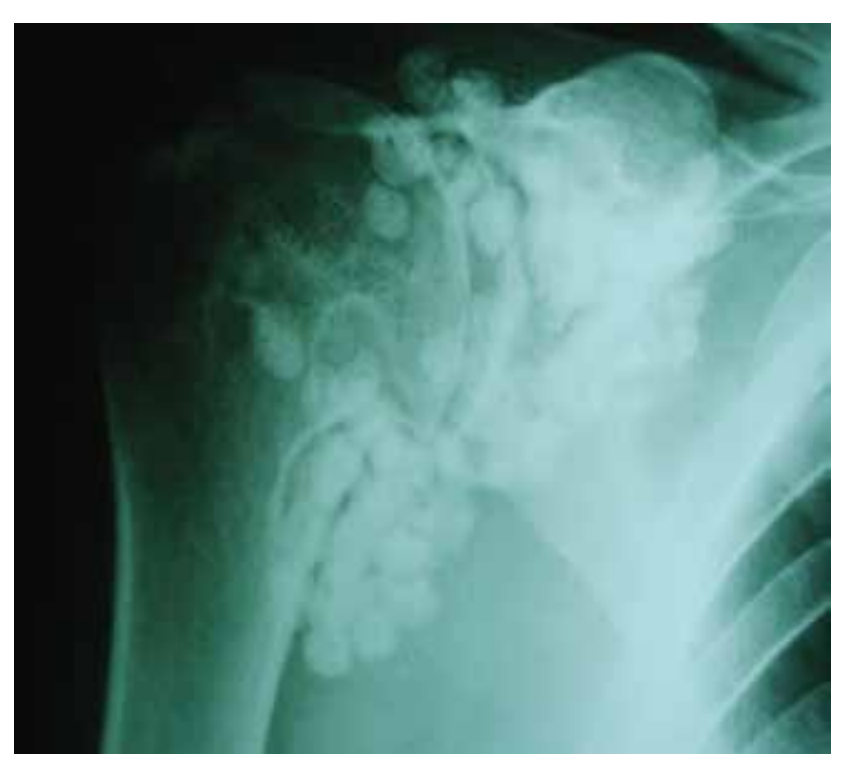

Figura 1. Rx de hombro derecho.

\begin{tabular}{|l|}
\hline Laboratorio \\
\hline Hemograma normal \\
\hline VSF: 3 mm \\
\hline PCR negativa \\
\hline Hepatograma normal \\
\hline Factor Reumatoideo negativo \\
\hline Anti CCP negativo \\
\hline FAN negativo \\
\hline Uricemia: 5,4 mg/dl \\
\hline Metabolismo P/Ca normal \\
\hline PTH normal \\
\hline 25 OH vitamina D: 37,8 nanogr/ml \\
\hline Perfil tiroideo normal \\
\hline
\end{tabular}

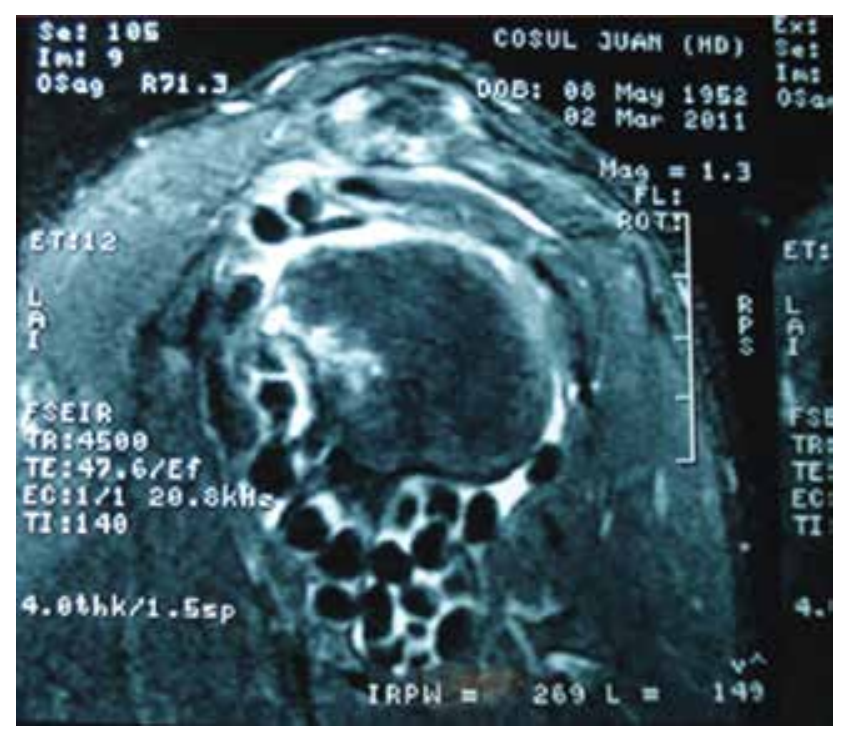

Figura 2. RMN de hombro derecho.

\section{Discusión}

La osteocondromatosis sinovial primaria o idiopática es una entidad poco frecuente caracterizada por la formación de nódulos cartilaginosos múltiples de las membranas sinoviales, muchos de los cuales se separan y quedan libres. Fue primariamente descripta por Laennec en 1813, pero fueron Jaffe y colaboradores los que en 1958 le otorgaron ese nombre. Otros sinónimos son condromatosis sinovial, condrometaplasia sinovial, osteocondritis disecans y encondrosis articular. Existen dos formas clínicopatológicas, la primaria y la secundaria a otras entidades articulares.

La patogénesis exacta de la forma primaria es desconocida y muchos autores concuerdan en que existe una metaplasia reactiva benigna sinovial sin la existencia de historia significativa de trauma articular, infecciones $u$ otros procesos inflamatorios sinoviales. En los niños no existe factor congénito o genético identificado en forma absoluta, y publicaciones recientes teorizan acerca de un

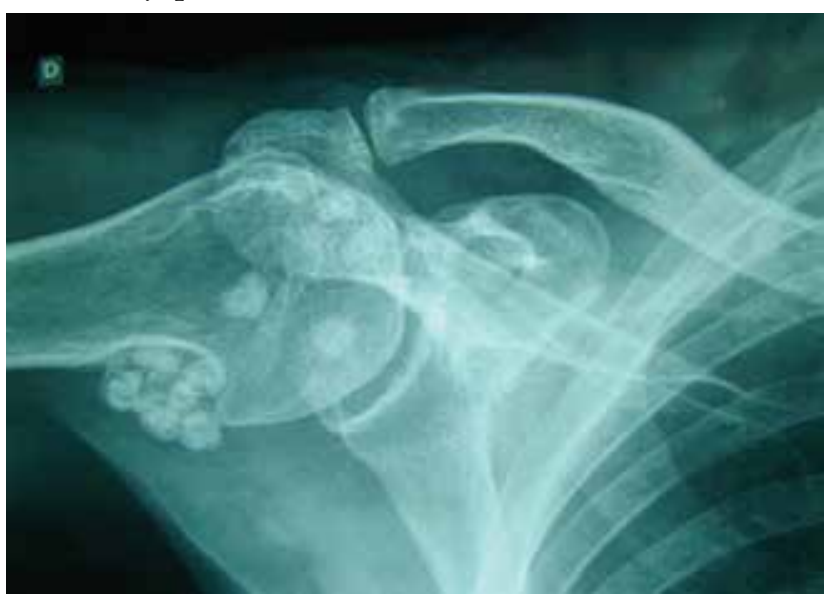

\section{Figura 3. Rx oblicua de hombro derecho.}

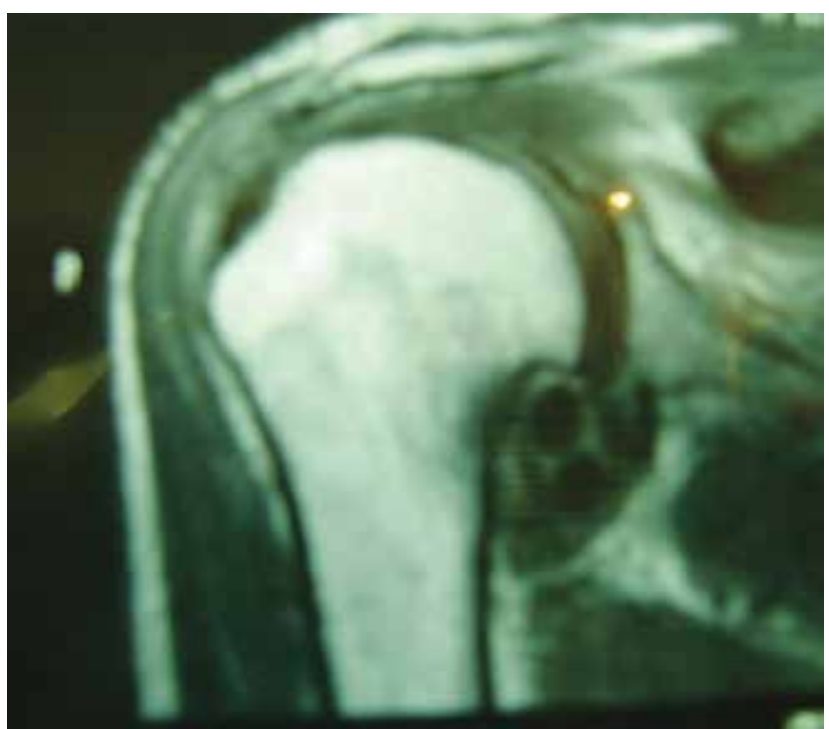

Figura 4. RMN de hombro derecho.

C. Ascimani Peña et al • Rev Arg Reumatol. 2016;27(2): 41-43 
desorden secundario de malformaciones cartilaginosas que se desprenden y fusionan con la sinovial, comenzando un proceso metaplásico.

Esta entidad ocurre siempre en las articulaciones o sectores periarticulares adyacentes, así como en vainas tendinosas o bursas, ocasionalmente. El estudio histopatológico demuestra nódulos grisáceos de 1 a 3 o más milímetros, casi siempre más concentrados en la unión condrosinovial, que denotan focos de cartílago hialino en el tejido conectivo sinovial, pudiendo presentar a veces hueso trabecular.

Las complicaciones más frecuentes incluyen a la osteoartritis degenerativa, bloqueos articulares, desprendimiento o rupturas tendinosas y eventualmente la transformación en condrosarcoma ${ }^{3}$.

$\mathrm{La}$ forma secundaria ocurre en relación con otros desórdenes articulares, tales como osteoartritis degenerativa, osteonecrosis, osteocondritis disecans, trauma, artropatía neuropática, artritis reumatoidea y artritis tuberculosa.

Los diagnósticos diferenciales más frecuentes corresponden a la artritis séptica (particularmente la tuberculosa), sinovitis vellonodular pigmentada, artritis reumatoidea, osteoartritis y algunas neoplasias como el sinoviosarcoma. También se destacan otras entidades como la artritis gotosa, condrocalcinosis, esclerodermia y condromas o condrosarcomas.

Si bien el tratamiento de elección es quirúrgico, ya sea por artroscopia o a cielo abierto, realizando la extracción de los nódulos más sinovectomia, la recidiva es de 0 a $31 \%$.

Milgram y Dunn describieron las tres fases ya mencionadas anteriormente y postularon que la fase de metaplasia con cuerpos libres es más recidivante al tratamiento quirúrgico.

Robinson y cols. describieron el posible rol del factor de crecimiento del fibroblasto $9 \mathrm{y}$ del factor de crecimiento del fibroblasto receptor 3, mientras que Sato describió el del factor de crecimiento del fibroblasto 2 y el factor de crecimiento del fibroblasto receptor 1 , y ambos plantearon la hipótesis de la posible terapia no quirúrgica ${ }^{4,5}$.

Basados en nuestra experiencia sobre el uso del metotrexato en las enfermedades reumáticas inflamatorias es que nos planteamos esta terapia en una enfermedad metaplásica que se comportó como inflamatoria y que no mejoró con el tratamiento quirúrgico, logrando la resolución casi completa de los nódulos condromatosos: una serendipia. (Una serendipia es un hallazgo afortunado e inesperado que se produce cuando se está buscando una cosa distinta.)

Hacen falta más trabajos para establecer la opción de tratamiento no quirúrgico planteada por Robinson y Sato desde el año 2000 hasta el 2002, pero puede resultar una novedosa alternativa terapéutica en los pacientes recidivantes al tratamiento quirúrgico, apoyados en el conocimiento del efecto antiproliferativo de esta droga sobre el fibroblasto sinovial como sucedió en nuestro caso ${ }^{4,5,14}$.

No hemos encontrado en la bibliografía ningún otro caso en el que se haya utilizado metotrexato para tratar esta patología.

\section{Bibliografía}

1. Jiménez-Martín A. et al. Reumatol Clin. 2014; 10(6):416-417.

2. Milgram JW. Synovial osteochondromatosis: A histological study of thirty cases. J Bone Joint Surg Am. 1977; 59:792-801.

3. Gómez-Rodríguez $\mathrm{N}$ et al. Condromatosis sinovial. Estudio de 39 pacientes. Reumatol Clin. 2006; 2(2):58-63.

4. Robinson D. et al. Int. Synovial chondromatosis: the possible role of FGF 9 and FGF receptor 3 in its pathology. J Exp Path. 2000; 81:183-189.

5. Sato J, Segami N, Suzuki T, Yoshitake Y, Nishikawa K. The expression of fibroblast growth factor-2 and fibroblast grow th factor receptor-1 in chondrocytes in synovial chondromatosis of the temporomandibular joint. Report of two cases. Int J Oral Maxillofac Surg. 2002; 31:532-536.

6. Duymus TM, Yucel B, Mutlu S, Tuna S, Mutlu H, Komur B. Arthroscopic treatment of synovial chondromatosis of the shoulder: A case report. Ann Med Surg (Lond). 2015 May 11; 4(2):179-82. doi: 10.1016/j. amsu.2015.05.001. eCollection 20.

7. Lorusso G, Sarma D, Sarwar S. Pathologic Quiz Case: Soft tissue calcifications of the shoulder in a 31 year-old woman. Arch Pathol Lab Med 2004;128(12):1455-1456.

8. Miranda J, Hooker S, Baechler M, Buerkhalter W. Synovial Chondromatosis of the shoulder and biceps tendon sheath in a 10 - year-old child. Orthopedics 2004;27(3):321-323.

9. Campeau N, Lewis B. Case report: Ultrasound appearance of synovial osteochondromatosis of the shoulder. Mayo Clin Proc 1998;73(11):1079-1081.

10. Ko E, Mortimer E, Fraire A. Extraarticular synovial chondromatosis: Review of epidemiology, imaging studies, microscopy and pathogenesis, with a report of an additional case in a child. International Journal of Surgical Pathology 2004;12(3): 273-280.

11. Mohr W. Is synovial osteo-chondromatosis a proliferative disease?. Pathol Res Pract 2002;198(9):585-589.

12. Peetrons P, Court-Payen M. Interventional procedures in musculoskeletal ultrasound. Seminars in interventional radiology, musculoskeletal interventional. Radiology 2002;19(3):189-196.

13. Lieger O, Zix J, Stauffer-Brauch EJ, Iizuka T. Synovial chondromatosis of the temporomandibular joint with cranial extension: a case report and literature review. J Oral Maxillofac Surg 2007;65:2073-80.

14. Hecht D, Zimmerman N, Bedford M, Avivi A, Yayon A. Identification of fibroblastic growth factor 9 (FGF9) as a high affinity, heparin dependent ligand for FGF receptors 3 and 2 but not for FGF receptors 1 and 4 . Growth Factors 1995;12:223-33. 